\title{
Analysis of the integration of Yakut isolated power system into the interconnected power system of Far East
}

\author{
Igor V. Ryabykh ${ }^{1, *}$, and Sergei V. Podkovalnikov ${ }^{1}$ \\ ${ }^{1}$ Melentiev Energy Systems Institute of Siberian Branch of the Russian Academy of Sciences, Electric Power Systems Department, \\ 664033, 130, Lermontov St., Irkutsk, Russia
}

\begin{abstract}
This article considers overview of the integration process of the isolated power systems of Yakutia to the eastern section of the Unified Power System of Russia. Features of development of Yakutia's electric power sector are considered. Systemic effects of connecting the isolated power systems of Yakutia to the IPS of Far East were identified. Changes in the electric power tariff setting were analysed. Information about improving of reliability of electricity supply was presented.
\end{abstract}

\section{Introduction}

The electric power industry of Yakutia, due to geographical and climatic features, as well as the specifics of the territorial location of industrial production facilities and settlements, has a number of characteristic features. First of all, it is the presence of a large number of small and distributed over a large area of non-industrial consumers of electricity along with large industrial and urban utility consumers of electricity. Under the influence of these conditions, zones of centralized and decentralized power supply were formed in the Republic, covering industrially developed centers and urban agglomerations, and in the second case, mainly economically poorly developed northern territories with separate "intersperses" of extractive industries, with a predominance of the population leading a traditional way of life.

In the works of the Institute of Physical and Technical Problems of the North (IPTPN), SB RAS has proposed their integration into the Interconnected Power System (IPS) of Far East as a modernization of the autonomous power systems of Yakutia [1].

In 1980, the South-Yakut isolated power system (SYIPS), which is closest to the IPS of Far East, was synchronized with it [2]. Further integration of the isolated power systems of Yakutia, including the Western (WIPS) and Central (CIPS) ones, was proposed by the representative of the IPTPN, Doctor of Technical Sciences, Professor N. A. Petrov. At the First Siberian Energy Congress, held in Novosibirsk in 2005, Professor Petrov proposed to form the United Power System of Eastern Siberia and the Far East [1].

In 2006, a scheme for the integrated development of the industry, transport, and energy of the Republic of Sakha (Yakutia) for the period from 2007 to 2020 was approved. In this document, one of the priority directions for the development of the fuel and energy complex in the period up to 2020 was the unification of the Central, Southern, and Western isolated power systems with each other, as well as with the IPS of Siberia and the IPS of Far East [3].

The starting point for the implementation of the strategy of connecting the isolated energy systems of Yakutia to the Unified Power System of Russia (UPS) can be called the implementation of the "northern" option of laying the main oil and gas pipeline (ESPO, Power of Siberia), adopted, including at the insistence of the leadership of the Republic of Sakha (Yakutia) and the Irkutsk region.

The Central and Western isolated power systems of the Republic of Sakha (Yakutia) were joined to the Unified Power System of Russia and Synchronized with the IPS of Far East on January 1, 2019 [2].

\section{Overview of the electric power industry of Yakutia}

The northern location of the region, the harsh natural and climatic conditions, the geographical remoteness of settlements and power centers, the vastness of the territory and low population density, the availability of mineral resources have led to the formation of special zones of centralized and decentralized power supply with electricity distribution at a voltage of $10,35,110$ and $220 \mathrm{kV}$.

The zones of decentralized power supply are located mainly in the north of the Republic. They consist of a large number of small autonomous power centers that provide energy to individual villages and mining enterprises. The set of northern zones of decentralized power supply was named the Northern isolated power

\footnotetext{
Corresponding author: ivryabykh@isem.irk.ru
} 
system. Its electricity supply is mainly provided by diesel power plants (DPP) [2].

Some decentralized zones receive electricity from neighboring regions. The Oymyakonsky district is supplied with electricity from the Magadan power system through two overhead transmission lines: OHTL of $220 \mathrm{kV}$ Arkagalinskaya STPP - Ust-Nera (operates at $110 \mathrm{kV}$ ) and the OHTL of $110 \mathrm{kV}$ Arkagalinskaya STPP - Nera. The Chersky settlement is supplied with electricity from the Chaun-Bilibinsky power center of the Chukotka Autonomous Okrug through the one OHTL of $110 \mathrm{kV}$ Vstrechny - Chersky [2].

By the 1970s, a centralized power supply zone was formed on the territory of Yakutia, including three isolated power systems: the South-Yakut isolated power system, near the border with the Amur region, the Western isolated power system, on the border with Eastern Siberia, and the Central isolated power system, around the city of Yakutsk. All of them worked independently, there were no electrical connections between them [4].

The Western isolated power system unites AikhalUdachninsky, Mirninsky, Lensky industrial hubs, a group of Vilyuysky agricultural districts, and Olekminsky district. The main sources of electricity supply to consumers of the Western isolated power system are the Vilyuyskaya hydroelectric power plant (HPP) cascade and the Svetlinskaya HPP. The Western isolated power system generates an excess amount of electricity and supplies these surpluses to the Irkutsk region via two OHTL of $220 \mathrm{kV}$ Peledui - OPS-9 No. 1,2 and OHTL of $220 \mathrm{kV}$ Peledui - Sukhoi Log No. 1,2 [5]. These lines provide electricity to the gold mining enterprises of the Bodaibinsky district of the Irkutsk region and the objects of the ESPO oil pipeline - oil pumping stations OPS-9 and OPS-8 [6].

In addition, the power plants of "Surgutneftegaz" JSC, namely the Talakanskaya gas-turbine power plant (GTPP), gas reciprocating power plant (GRPP), and several DPP, operate in isolation on the territory of the Western isolated power system. They provide electricity to the industrial facilities of the Talakan OGCF, and since 2009 they have been providing electricity to the ESPO oil pipeline facility OPS-10 through two singlecircuit OHTL of $110 \mathrm{kV}$ overhead lines of the Talakan GTPP - OPS-10 [2].

The Central isolated power system provides electricity to the central industrial hub, including the city of Yakutsk, a group of central districts and districts on the right bank of the Lena River. The main sources of electricity supply to the consumers of the CIPS are the Yakutskaya GTPP and the Yakutskaya GTPP-2, as well as the Yakutskaya combine heat and power plant (CHP) [2].

The South-Yakut isolated power system provides electricity to the South-Yakut territorial-industrial complex, as well as to the Neryungrinsky and Aldan industrial and agricultural hubs. The main sources of electricity supply to consumers of the South-Yakut isolated power system are the Neryungrinskaya steamturbine power plant (STPP) and the Chulmanskaya CHP. These power plants provide electric energy not only to consumers of the Neryungrinsky and Aldan districts but a significant part of it is transferred to the Amur region [2].

Since 1980, the SYIPS has been working as a part of the IPS of Far East. Communication with it is carried out through the Amur power system via 2 parallel circuits of $220 \mathrm{kV}$ cable and overhead lines Neryungrinskaya STPP - Tynda No. 1,2 [2].

\section{Prerequisites for joining the local power system of Yakutia to the IPS of Far East}

The issue of joining the Central and Western isolated power systems to the IPS of Far East has not been raised at the official level until 2009. Both isolated power systems worked in a balanced way: they were redundant, the installed capacity of their generation facilities covered current consumption, natural gas for the operation of the power plants in CIPS was extracted on the territory of the Republic, and the rapid development of the industrial load was not predicted [4].

At the same time, the accession to the IPS of Far East had a number of objective prerequisites.

First, the region has high electric power tariffs. On the one hand, this is objectively due to the high costs of producing and delivering electricity to geographically remote consumers in the harsh natural and climatic conditions of Yakutia. On the other hand, due to the limited capacity of isolated power systems to provide optimal operating modes of power equipment, there is an additional increase in operating costs, in particular their fuel component.

Since the population is a socially protected category of consumers, high electric power tariffs were set for other groups of consumers - industrial enterprises and entrepreneurs. They were forced to buy electricity at inflated prices, thereby increasing the cost of their products and reducing profitability [7].

Secondly, the number of accidents in the electric power industry of the republic gradually increased, and some of them led to the disconnection of electricity consumers. There is limited transmission capacity of power transmission lines and substation equipment, deterioration of generating sources, which is the cause of frequent accidents and shortages of electricity in consumption nodes. A particularly difficult situation in terms of reliability has developed in Central Yakutia and in the city of Yakutsk [1].

\section{Priority steps for joining the isolated power systems of Yakutia to the IPS of Far East}

In 2007, the proposal of the Department of Energy Problems of the IPTPN SB RAS together with the republican leadership on the unification of the IPS of Siberia and the Far East through the power centers of centralized power supply of the Republic of Sakha (Yakutia) was submitted to the Minister of Industry and 
Energy of the Russian Federation V. B. Khristenko. Then this proposal was presented to the First Deputy Prime Minister of Russia S. B. Ivanov, who supported this progressive idea.

The first discussions at the official level began during the construction of the "Eastern Siberia-Pacific Ocean" (ESPO) oil trunk pipeline, which was being built to transport Russian oil to the promising market of the Asia-Pacific region. The implementation of this largescale project involves the construction of an appropriate power grid infrastructure, which is necessary for the electricity supply, first of all, of substations feeding oil pumping stations [4].

In the period from 2009 to 2010, the branch of Federal grid company of Unified Power System (FGC UPS) - the Far Eastern grid company - put into operation the second $220 \mathrm{kV}$ transmission line Neryungrinskaya STPP - Nizhny Kuranakh. This made it possible to create conditions for connecting new consumers to the main networks, including the facilities of the ESPO oil pipeline system. In particular, according to these networks, the electricity supply of OPS-17 was established [8].

The $220 \mathrm{kV}$ transit lines under construction were considered for the organization of electric connections between the South-Yakut and Western isolated power systems, which meant the implementation of parallel work with the IPS of Far East. Also, in the future, the project of connecting the Central isolated power system began to be considered again. As a result, it was decided to start work on the connection of WIPS and CIPS to the IPS of Far East [4].

The construction of power grid facilities directly to provide electrical connections of isolated power systems was carried out from 2012 to 2018.

\section{Work made on the connection of the isolated power systems of Yakutia to the IPS of Far East}

\subsection{Administrative activities}

Until 2006, "Yakutskenergo" JSC performed the functions of operational and dispatching control of electric power facilities on the territory of the WIPS, CIPS and SYIPS.

On October 19, 2006, SYIPS was introduced into the operating zone of the branch of "SO UPS" JSC "Regional Dispatching Center of the Amur Region Power System" (Amur RDC) [9].

In connection with the beginning of the implementation of plans for the connection of isolated power systems, on December 17, 2012, a representative office of the System Operator was opened in Yakutia, which was caused by the need to prepare in advance for the reception of the functions of operational dispatch management [4].

In 2015, the branch of "SO UPS" JSC - ODE of the East - started working on the possibility of synchronous operation of the Western isolated power system with the IPS of Far East [10].

On February 1, 2016, the branch of "SO UPS" JSC "Regional Dispatching Center of the Power System of the Republic of Sakha (Yakutia)" — Yakut RDC — started working in Yakutsk. This branch was created in preparation for the implementation of operational and dispatching management of electric power facilities in the Western and Central isolated power systems of Yakutia after their accession to the IPS of Far East $[4,11]$.

The System Operator trained specialists of the Yakut RDC to accept the functions of operational and dispatching control on the territory of the WIPS and the CIPS. The state certification of dispatching personnel was carried out, a list of dispatching facilities was developed, calculation models and databases of software and hardware complexes and software were formed, as well as documentation regulating all aspects of electric power management was developed [12].

During the implementation of measures for the connection of isolated power systems to the IPS of Far East, the specialists of the System Operator took part in the preparation and approval of technical tasks for the development of project documentation. They reviewed and agreed on the design and working documentation, agreed on the technical conditions for the technological connection of power grid facilities to the electric networks, and participated in the verification of the fulfillment of these technical conditions [13].

In December 2017, the readiness of the branch of "SO UPS" JSC Yakut RDC to assume the functions of operational and dispatching control in the territory of the Western and Central isolated power systems was confirmed [12].

In preparation for the synchronization of the new isolated power systems with the UPS, the System Operator's specialists performed calculations of electric power modes, short-circuit currents, and the values of the maximum permissible active power flow in the controlled sections. They also calculated the settings of relay protection and automation devices and issued them to the operational personnel of power facilities [4].

A set of regime measures to ensure the inclusion of the Western and Central isolated power systems in the UPS was developed and implemented by the branches of "SO UPS" JSC - the ODE of the East, the Yakut RDC, and the Amur RDC.

In December 2018, the process of forming the regulatory framework necessary for the expansion of the Unified Power System of Russia through the connection of the Western and Central isolated power systems was completed at the state level [13].

On January 1, 2019, the System Operator assumed the functions of operational dispatch management in the Western and Central isolated power systems [5]. These isolated power systems were included in the operating zone of the branch of "SO UPS" JSC - Yakut RDC [14].

\subsection{Construction of electrical grids}


In 2014, in preparation for the accession of Yakutia to the IPS of Far East, the connection of the South-Yakut and Western isolated power systems was created. "FGC UPS" JSC together with "DVEUK" JSC completed the construction of the OHTL of $220 \mathrm{kV}$ Gorodskaya (Lensk) - Olekminsk - OPS-15 - Nizhny Kuranakh with the tap at OPS-16. In the period from 2014 to 2018, the SYIPS and WIPS operated out of sync, with the split point at the OPS-15 bus $[6,15]$.

The organization of electrical connections of the Central and South Yakut isolated power systems was handled by "FGC UPS" JSC. In 2018, the project of connecting the Central isolated power system was completed, which consists in the construction of the OHTL of $220 \mathrm{kV}$ Neryungrinskaya STPP - Nizhny Kuranakh - Tommot - Maya overhead line, the $220 \mathrm{kV}$ Maya substation and the $220 \mathrm{kV}$ transit substation Tommot [16].

In order to connect the $110 \mathrm{kV}$ distribution network of the Central isolated power system to the $220 \mathrm{kV}$ electric networks of "FGC UPS", "Yakutskenergo" completed the construction of power transmission lines to the $220 \mathrm{kV}$ Maya substation and the reconstruction of a number of existing substations in 2018 [17].

\subsection{Tests for stable operation of WIPS and the IPS of Far East}

On March 22, 2016, full-scale tests of the synchronous operation of the IPS of Far East and the WIPS took place. The aim was to determine the main characteristics, indicators, and operating conditions of the synchronous operation of the Western isolated power system with the IPS of Far East. Also, the task of the tests was to verify the calculation models of the Western isolated power system and the IPS of Far East for the calculations of steady-state modes and static stability, transient modes, and dynamic stability [4].

According to the commands of the dispatching personnel of the ODE of the East, the synchronization of the Western isolated power system with the IPS of Far East was carried out and the regulation of power flows through intersystem connections was carried out. The flow rate was regulated by changing the generation of the Vilyui HPP cascade [4].

The tests carried out by the System Operator confirmed the possibility of parallel operation of the previously isolated power system of the republic as part of the IPS of Far East as part of the Unified Power System of Russia [11].

During the tests, the stable synchronous operation of the Western isolated power system with the IPS of Far East was ensured, and the experimental data obtained were used in the development of measures to ensure the possibility of constant synchronous operation of the WIPS with the IPS of Far East. Thus, based on the test results, a feasibility study was developed for the creation (reconstruction) of relay protection and automation system in the operating zone of the Yakut RDC [4].

\subsection{Tests for stable operation of CIPS and the IPS of Far East}

In the spring of 2018, a full-scale experiment was successfully conducted, which proved the possibility of restoring electricity supply to consumers of the Central isolated power system of Yakutia from the IPS of Far East by transferring the split point between them [13].

The purpose of the experiment was to work out the actions of dispatching and operational personnel when restoring electricity supply to districts located on the right bank of the Lena River in the Central isolated power system from the IPS of Far East through the cable and overhead lines of $220 \mathrm{kV}$ Nizhny Kuranakh - Maya [4].

During the experiment, the point of separation between the IPS of Far East and the CIPS was successfully moved closer to the center of the isolated power system. As a result of the experiment, some consumers received electricity from the IPS of Far East [13].

As a result, the possibility of restoring the electricity supply to districts located on the right bank of the Lena River from the IPS of Far East in the event of accidents on generating equipment was confirmed [4].

\section{Efficiency of integration of the Yakut isolated systems into the IPS of Far East}

The first effect of joining the isolated power systems to the IPS of Far East was a drastic increase in the reliability of electricity supply to consumers. This was most relevant for the Central isolated power system, where the main consumption is not industrial, but domestic, primarily the Yakutsk city [4].

Until recently, accidents on generating equipment under the conditions of isolated operation of CIPS during the maximum loads characteristic of the long and severe Yakut winter often led to the disconnection of consumers. In 2018, there were eleven cases of power outages from 12 to 90 thousand people at the same time [4].

In the first quarter of 2019 (i.e., after the connection of the CIPS to the IPS of Far East), three accidents were recorded with the shutdown of generating equipment at the Yakutskaya GTPP-2. However, they did not lead to the disconnection of consumers, as power was transferred from the IPS of Far East. In the Western isolated power system, a similar result was achieved with the start of parallel work with the IPS of Far East, the shutdown of any hydro generator of the Vilyuyskaya HPP cascade, or the Svetlinskaya HPP no longer led to the disconnection of consumers. In the first quarter of 2019, six accidents with power outages occurred in the CIPS and WIPS, while in the same periods of 20162018, an average of 20 such accidents occurred [4].

The statistical increase in reliability is shown using System Average Interruption Frequency Index (SAIFI) and System Average Interruption Duration Index (SAIDI), the graphs of which are shown in figure 1. This 
graph provides information on "Yakutskenergo" JSC, assets of which include: Vilyuyskaya HHP cascade, Yakutskaya GTPP, Yakutskaya GTPP-2, Yakutskaya CHP and a number of DPP on the territory of the WIPS and CIPS [18].

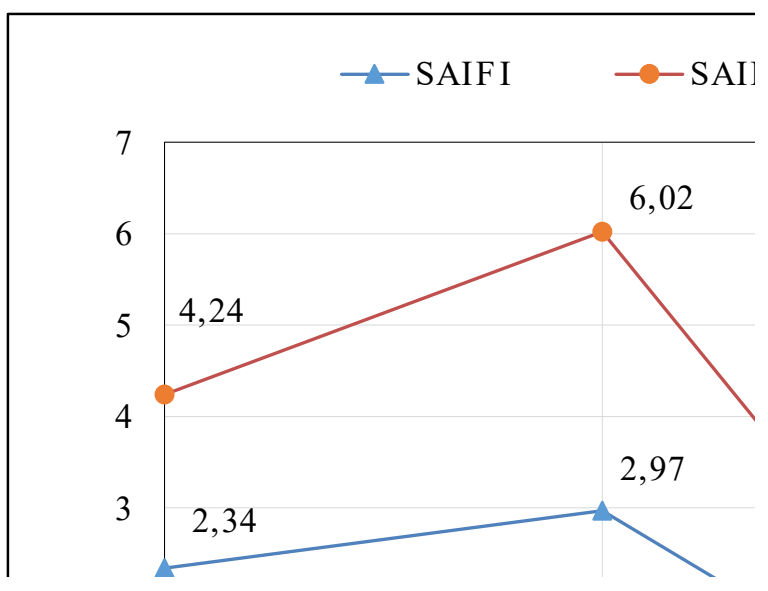

Fig. 1. Reliability indexes of JSC "Yakutskenergo".

The second effect is economic. With the addition of the Yakut isolated power systems to the IPS of Far East, it became possible for the System Operator to optimize the generation load in the entire IPS of Far East in its new extended configuration. Taking into account the introduction of the procedure for selecting the composition of the included generating equipment in the IPS of Far East in 2019, which is one of the main tools of the wholesale market in the UPS, the impact of the integration of the Yakut isolated power systems and the IPS of Far East can be quite noticeable [4].

Also, the economic effect is due to the fact that the CIPS and WIPS, which are attached to the IPS of Far East, joined the "regulated" zone of the wholesale market. At the same time, there have been changes in the electric power tariff setting. Previously, generating companies supplied electricity directly to consumers. To regulate prices, there was a constant final electric power tariff.

As a result, final tariff is not approved for enterprises and entrepreneurs from January 1, 2019. Now generating stations sell electricity to the wholesale market, and the guaranteeing supplier - "Yakutskenergo" - buys energy at hourly changing prices and trades with enterprises and entrepreneurs without a final tariff. This guarantees the optimization of the electricity production process in the entire IPS of Far East and leads to a reduction in the price of electricity for the above-mentioned group of consumers.

These changes indirectly influenced the government's decision to reduce the share of subsidies to the Yakut energy sector (see Figure 2). In 2017, Yakutia introduced subsidies aimed at reducing high electric power tariffs for consumers who are not related to the population. First of all, this subsidy was intended for the Northern isolated power system, in which electric energy was generated by diesel power plants [19].

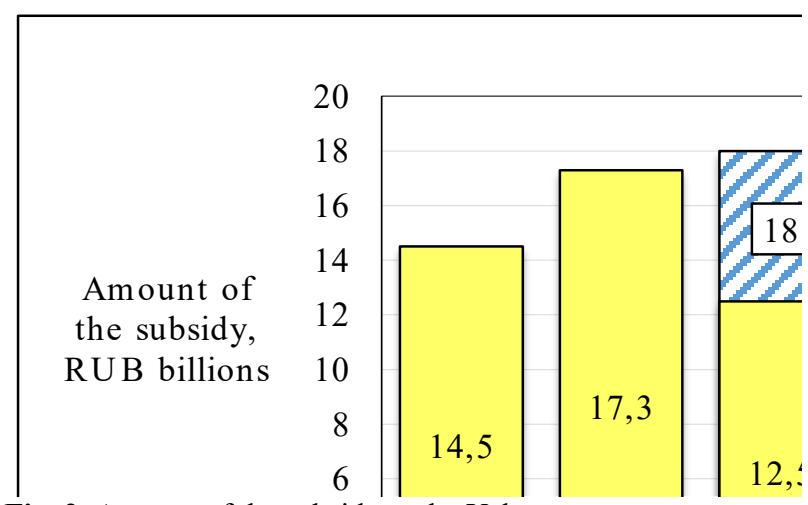

Fig. 2. Amount of the subsidy to the Yakut energy sector.

In connection with the transition to the non-price zone on January 1, 2019, the subsidy for tariff equalization was canceled in the Central, Western, and South Yakut isolated power systems. Amount of the subsidy redused from 18 to 12,5 billions rubles.

A decrease in the cost of electricity was recorded in the entire IPS of Far East. Based on the data of the Association "NP Market Council", the average purchase price of planned volumes of electricity in the wholesale market decreased by an average of 12 percent in 2019 (see Figure 3). It is worth noting that these average prices refer to the planned volumes for the population. However, a significant reduction in the regulated price also suggests that the connection of the Yakut isolated power systems has a positive impact on the economy of the Far East [20-21].

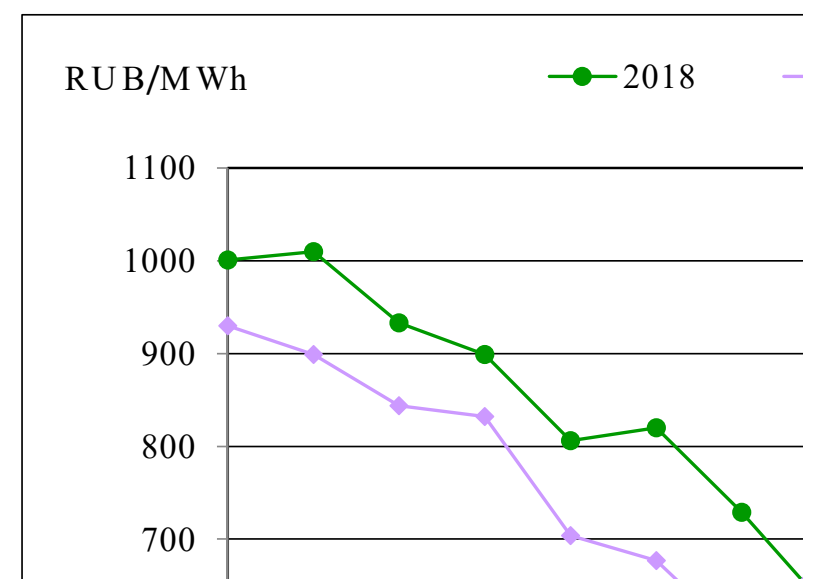

Fig. 3. Average purchase price of planned volumes of electricity in the wholesale market of the Far East.

Another effect of the connection of isolated power systems to the Unified Power System is that the quality and volume of telecommunications services provided to consumers has increased in the republic. During the construction of new power lines, a $464 \mathrm{~km}$ long fiberoptic communication line (FOCL) was laid.

First of all, it was required for the transmission of technological and corporate information to the power grid company. FOCL creates the basis necessary for the introduction of digital technologies into the backbone network complex, such as digital substation, remote control, remote observability, the introduction of digital accounting, and others. However, the bandwidth of such 
a channel allows you to use part of its resources to provide communication services to external consumers, which helps to optimize the capital costs of telecommunications companies for the construction of infrastructure. This is primarily relevant for remote regions.

In the case of the Neryungrinskaya STPP - Nizhny Kuranakh - Tommot - Maya energy transit, part of the channels was leased to Rostelecom. Previously, the population and industry of the center of the region were provided with communication using radio relay lines, which means less bandwidth. The new infrastructure made it possible to increase the quality and range of services, including the provision of broadband Internet access.

\section{Conclusions}

The territorial expansion of the UPS continues due to integration with the previously isolated power systems of Yakutia. This leads to an increase in the reliability of electricity supply to consumers, which confirms the feasibility of such integration. Economic indicators of Yakutia's electric power sector were improved after integration of CIPS and WIPS into the IPS of Far East. Integrating of isolated power systems had also the accompanying effect of increasing the quality of telecommunications services and the range of ones to the population and the industry of Yakutia.

This integration, so-called "internal", is a local example of the implementation of the global trend of electric power integration with the formation of interstate interconnections, at the level of a single country.

Further development of "internal" integration can occur due to the connection of isolated energy systems of the Far East to the IPS of Far East. Moreover, this connection can be accompanied by an "external" (interstate) electric power integration, when, for example, an electric connection between the mainland of the Russian Far East and the island of Sakhalin can also be used to ensure the subsequent export of electricity to Japan.

As part of the further work, it is planned to calculate the system technical and economic effects of the integration of the isolated power systems of Yakutia and the IPS of Far East using a mathematical model of the development and operating modes of power system.

The research was carried out under State Assignment Project (no. FWEU-2021-0001) of the Fundamental Research Program of Russian Federation 2021-2030.

\section{References}

1. N.A. Petrov, Resource potential of the Republic of Sakha in building energy hubs of the East of Russia, Oil and Gas Vertical J. 150, 76 (2006) [in Russian]
2. The scheme and program to develop the electric power sector of the Republic of Sakha (Yakutia) in 2019-2023 [in Russian]

3. The scheme for the integrated development of the industry, transport, and energy of the Republic of Sakha (Yakutia) up to 2020 [in Russian]

4. Attainment of the Yakutia, 50 Hertz corporate J., 33, 3 (2019) [in Russian]

5. The scheme and program to develop the electric power sector of the Republic of Sakha (Yakutia) in 2020-2024 [in Russian]

6. The scheme and program to develop the electric power sector of the Republic of Sakha (Yakutia) in 2018-2022 [in Russian]

7. N.S. Kuz'minov, G.I. Nikiforova, Crosssubsidization in power Sakha Republic (Yakutia), Problems of economics and management, 64, 50 (2016) [in Russian]

8. Open Joint-Stock Company "Federal Grid Company of Unified Energy System" annual report 2010. https://www.fsk-ees.ru/upload/docs/fsk_en/ en/20110712_fsk_ar2010_eng_preview.pdf Russian]

9. Joint-Stock Company "System Operator of the Unified Power System" annual report 2006. https://www.so-ups.ru/fileadmin/files/company/ reports/annual/2006/AR_SO___2006.pdf [in Russian]

10. Public Joint-Stock Company "Yakutskenergo" annual report 2015. https://yakutskenergo.ru/shareholders_and_investors/ open_information/Year-reports.php? $\overline{\text { year }}=\overline{2} 015 \#$ yearanch [in Russian]

11. Joint-Stock Company "System Operator of the Unified Power System" annual report 2016. https://www.so-ups.ru/fileadmin/files/company/ reports/annual/2016/annual_2016.pdf [in Russian]

12. Joint-Stock Company "System Operator of the Unified Power System" annual report 2017. https://www.so-ups.ru/fileadmin/files/company/ reports/annual/2017/annual_2017.pdf [in Russian]

13. Joint-Stock Company "System Operator of the Unified Power System" annual report 2018. https://www.so-ups.ru/fileadmin/files/company/ reports/annual/2018/annual_2018.pdf [in Russian]

14. Joint-Stock Company "System Operator of the Unified Power System" annual report 2019. https://www.so-ups.ru/fileadmin/files/company/ reports/annual/2019/annual_2019.pdf [in Russian]

15. Public Joint-Stock Company "Yakutskenergo" annual report 2014. https://yakutskenergo.ru/ shareholders_and_investors/open_information/Yearreports.php? year $=$ 2014\#yearanch [in Russian]

16. Public Joint-Stock Company "Federal Grid Company of Unified Energy System" annual report 2018. https://www.fsk-ees.ru/upload/docs/2018_ GO_FSK_EES_Smart_pril_1-12.pdf [in Russian] 
17. Public Joint-Stock Company "Yakutskenergo" annual report 2019. https://yakutskenergo.ru/ shareholders and investors/open information/Yearreports.php? year=2019\#yearanch [in Russian]

18. Public Joint-Stock Company "RusHydro" annual report 2019. http://www.eng.rushydro.ru/upload/ iblock/d44/Annual-report-2019-01.pdf [in Russian]

19. Federal Law No. 508-FZ of 16 December, 2016 "On amending Federal Law No. 35 On the Electric Power Industry" [in Russian]

20. Association "NP Market Council" annual report 2018. https:/www.np-sr.ru/sites/default/files/go_ 2018_god_.pdf [in Russian]

21. Association "NP Market Council" annual report 2019. https://www.np-sr.ru/sites/default/files/1_ godovoy_otchet_0.pdf [in Russian] 